OOPEN ACCESS

Engineering Science \& Technology Journal

Volume 2, Issue 1, P. 20-25, March, 2020

Fair East Publishers

Journal Homepage: www.fepbl.com/index.php/estj

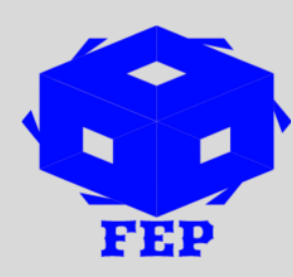

\title{
CASE OF PARTICLE ANALYSIS FOR SELECTED MATERIAL
}

\section{Reza Bezerra ${ }^{1}$, Santos Prates ${ }^{2}$}

${ }^{1,2}$ School of Electrical and Computer Engineering, University of Campinas, Brazil

*Corresponding Author: Reza Bezerra

Article Received: 11-10-19

Accepted: 13-01-20

Published: 27-03-20

Licensing Details: Author retains the right of this article. The article is distributed under the terms of the $\begin{array}{lllll}\text { Creative } & \text { Commons } & \text { Attribution-NonCommercial } & 4.0 & \text { License }\end{array}$ (http://www.creativecommons.org/licences/by-nc/4.0/) which permits non-commercial use, reproduction and distribution of the work without further permission provided the original work is attributed as specified on the Journal open access page

\section{ABSTRACT}

There are different types of material which can be used in laboratory settings. These materials possess different qualities. In this study, three types of cements including the Portland cement, calcium enhanced material, and the proroot MTA. For each category, 120 samples were taken and the average for Portland cement was 35.23 with SD of 5.23. The average of Calcium enhanced material was 41.87 with SD of 4.98. The average of Proroot MTA was 56.89 with SD of 6.73. The size range comparison based on particle analysis shows that among the three types, the MTA shows better results compare to the other types in terms of smaller particle range.

Keywords: Cement, Material, Comparison, Portland. Laboratory.

\section{INTRODUCTION}

For biomaterials, various particle size means changes in their properties. Greater dissolution is a quality more commonly found in smaller size particles compare to the larger particles (Prentice, Tyas, \& Burrow, 2005). The increased exposed area facilitates the working time reduction as found in previous study which utilized particle size analysis for assessing the X-ray photoelectron spectroscopy and particle size (Wren, Clarkin, Laffir, Ohtsuki, Kim, \& Towler, 2009). Thus, for improving mechanical properties, particle size distribution is important predictor (Guggenberger, May, \& Stefan, 1998).

Earlier work such as Kent and Wilson (1971) showed that particle size based on sieve technique has very moderate influence on compressive strength. Reduction in particle size is associated with increased abrasion resistance (Wang, DiBenedetto, \& Goldberg, 1998). Another study also shows that particle size has moderate influence on compressive strength (Brune \& Smith, 1982). 
Weakness of material is found to be influenced by larger mean particle size 6,7. A comparative study showed that materials with finer particle of about $(3.4 \mu \mathrm{m})$ were strong but too fast setting; while, material of larger particles of about $(\sim 10 \mu \mathrm{m})$ forms a non-cohesive and clay like paste. Higher compressive strength is noted in smaller particles of material compare to the larger particles (Xie, Brantley, Culbertson, \& Wang, 2000).

There are various methods of such analysis and laser diffraction is one popular method of material analysis (Locher, Sprung, \& Korf, 1994). In this study, laser diffraction method is used for analyzing two modules of dry and wet dispersion. For dry powder, dry dispersion is utilized; while, for emulsions and suspensions, wet dispersion is utilized. The dispersing module named as CUVETTE is considered as best suited for small quantities of valuable products and in situation where there is danger of destruction of particles or droplet due to the pumping. The two versions namely the $50 \mathrm{~mL}$ and $6 \mathrm{~mL}$ cover the particle size range from 0.1 to $3500 \mu \mathrm{m}$ (Lee, Monsef, \& Torabinejad, 1993).

SEM is also used for appraising the particle size of materials (Torabinejad, Watson, \& Ford, 1993). Higher mechanical strength can be achieved for smaller particle size by bringing reduction in grid size (Komabayashi \& Spangberg, 2008). In this regard, it is important to mention that a root-end filling material labelled as 'Mineral Trioxide Aggregate' is introduced in the past (Camilleri, Montesin, Di Silvio, \& Ford, 2005). It is mainly composed of Portland cement (Kogan, He, Glickman, \& Watanabe, 2006). ProRoot mineral trioxide aggregate has similar particle distribution as Portland cement (Asgary, Parirokh, Eghbal, \& Brink, 2004). The difference is that proroot mineral trioxide aggregate shows homogeneous image and equal particle sizes compare to the Portland cement which exhibits wider variety in its particle sizes (Asgary, Parirokh, Eghbal, \& Brink, 2004). However, despite some favorable qualities, the clinical disadvantages of mineral trioxide aggregate include higher price, handling cost, and extended setting time (Camilleri, et al., 2005) The mineral trioxide aggregate has to be mixed with sterile water as recommended by manufacturers. While mixing, the material transforms in to sand-like granular mixture which is hard to condense and pose logistic challenges (Kogan, et al., 2006). Comparative studies of two types of material including mineral trioxide aggregate and Portland cement shows that these two shows some similarities in terms of chemical characteristics and both are biocompatible (Lee, et al., 1993). By bringing particle modifications, the handling characteristics can be changed according to the desired need. Calcium enriched mixture is also a type of material and is shown good qualities such as easier handling and shorter setting time, film thickness and improved flow (Lee, et al., 1993)

The objective of the present study is to make comparison of the particle size of three various materials including Portland cement, Calcium enriched mixture, and the proroot MTA.

\section{EXPERIMENTAL DESIGN}

In the present study, three types of material including Portland cement, calcium enriched mixture, and proroot MTA were used in this experimental study. Particle size analyzer model namely disperser CUVETTE and HELOS were used with range measurement between 0.1 to $4000 \mu \mathrm{m}$. in the range of 0.1 to $4000 \mu \mathrm{m}$, the particle size analyzer is used for suspensions and 
emulsions using the wet technique. The technique of CUVETTE consists of two $6 \mathrm{~mL}$ glass tubes called model SM for measuring the particle size which were in the range of 0.1 to $40 \mu \mathrm{m}$; while, for $50 \mathrm{~mL}$ model US is used for particle size ranging from 0.30 to $4500 \mu \mathrm{m}$. For prevention of sedimentation and ultra sound for dispersing particles, mixer is available. The key information including mixture speed, power of ultrasonic, time, measurement, and reference time were recorded. $50 \mathrm{~mL}$ of alcohol or $90 \%$ of ethanol is poured in glass tube of every sample and mixed with suitable alcohol which result in a creamy mixture. The resulting creamy mixture is slowly added with glass tube for making optical concentration ranging from 15 to $25 \%$. Measurement is taken for dispersion of the particle sizes. The results are obtained and displayed in the table, charts, and interpretation as suitable.

\section{RESULTS}

Table 1: Descriptive Statistics

\begin{tabular}{|l|c|c|c|c|c|}
\hline \multicolumn{1}{|c|}{ Material } & Sample & Average & S.D. & Minimum & Maximum \\
\hline Portland Cement & 120 & 35.23 & 5.23 & 4.98 & 52.0 \\
\hline Calcium Enhanced Material & 120 & 41.87 & 4.98 & 5.93 & 99.0 \\
\hline Proroot MTA & 120 & 56.89 & 6.73 & 7.54 & 90.0 \\
\hline
\end{tabular}

The results show that for Portland cement, the minimum is 4.98, maximum is 52 and average is 35.23. For calcium enhanced material, the minimum is 5.93, maximum is 99 and average is 41.87. For Proroot MTA, the minimum is 7.54 , maximum is 90 , and average is 56.89 .

Table 2: Distribution of Particle Sizes between 0.5-30 $\mu \mathrm{m}$ related to Sample Materials

\begin{tabular}{|l|c|c|c|c|c|c|}
\hline Size range $(\boldsymbol{\mu m})$ & PC-Count & PC-\% & CEM-Count & CEM-\% & MTA-Count & MTA-\% \\
\hline $1-3$ & 34 & 28.33 & 33 & 27.5 & 32 & 26.67 \\
\hline $3.1-4.5$ & 20 & 16.67 & 37 & 30.83 & 26 & 21.67 \\
\hline $4.6-6$ & 19 & 15.83 & 21 & 17.5 & 21 & 17.50 \\
\hline $6.1-10$ & 32 & 26.67 & 18 & 15 & 19 & 15.83 \\
\hline Above 10 & 15 & 12.50 & 11 & 9.17 & 22 & 18.33 \\
\hline Total & $\mathbf{1 2 0}$ & $\mathbf{1 0 0}$ & $\mathbf{1 2 0}$ & $\mathbf{1 0 0}$ & $\mathbf{1 2 0}$ & $\mathbf{1 0 0}$ \\
\hline
\end{tabular}

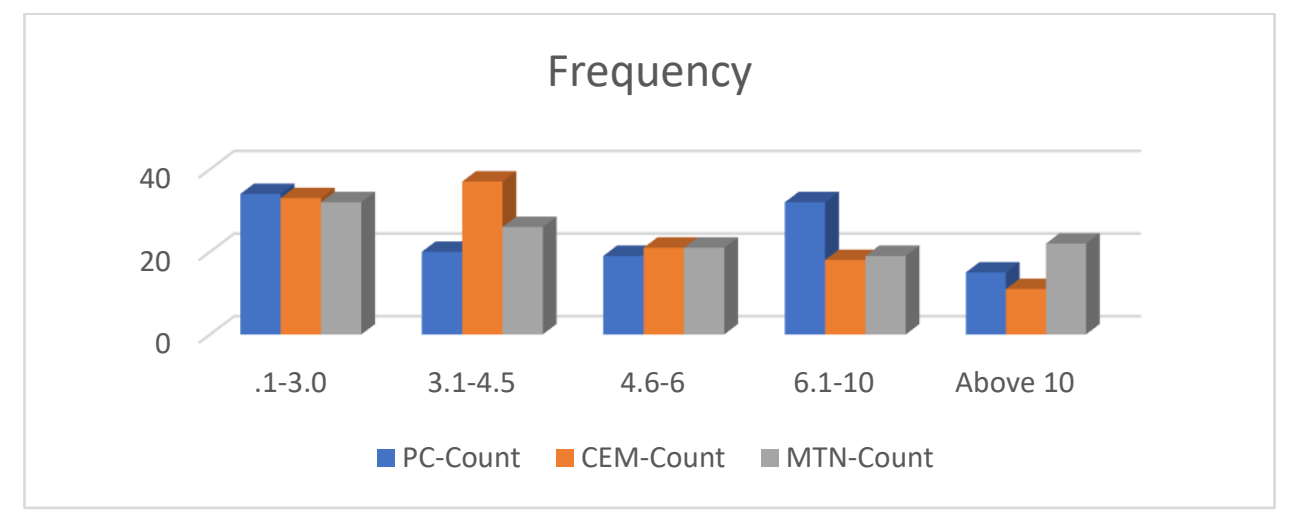

Figure 1: Distribution of Particle Sizes between 0.5-30 $\mu \mathrm{m}$ related to Sample Materials 


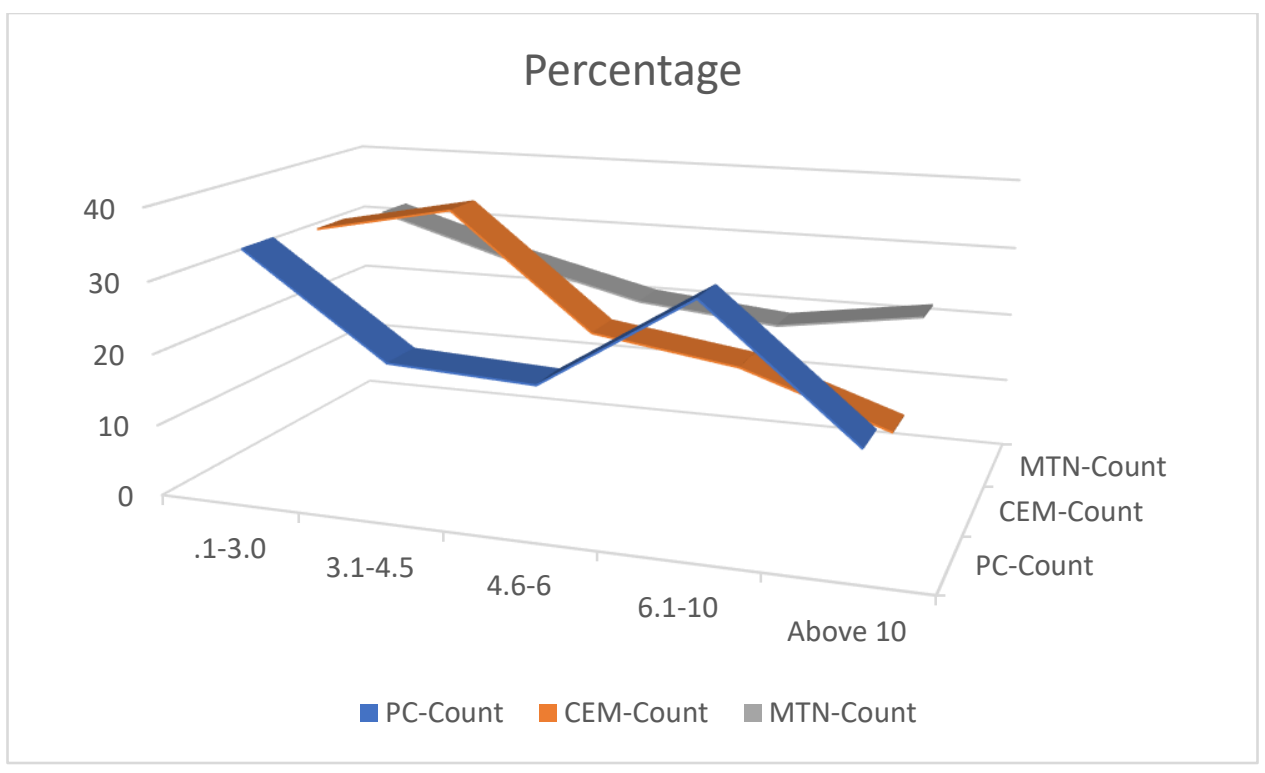

Figure 2: Distribution of Particle Sizes between 0.5-30 $\mu \mathrm{m}$ related to Sample Materials

The results show that on aggregate percentage basis, the material studied in the study including Portland cement, calcium enhanced material, and MTA showed no significant differences. For PC count, the size range was 34 for $1-3 \mu \mathrm{m} ; 20$ for 3.1 to $4.5 \mu \mathrm{m}$; 19 for 4.6 to $6 \mu \mathrm{m}$; 32 for 6.1 to $10 \mu \mathrm{m}$; and 15 for above $10 \mu \mathrm{m}$. Percentage wise, the number comes to $28.33 \%$ for $1-3 \mu \mathrm{m}$; $16.67 \%$ for 3.1 to $4.5 \mu \mathrm{m} ; 15.83 \%$ for 4.6 to $6 \mu \mathrm{m} ; 26.67 \%$ for 6.1 to $10 \mu \mathrm{m}$; and $12.5 \%$ for above $10 \mu \mathrm{m}$.

For calcium enhanced material count, the size range was 33 for $1-3 \mu \mathrm{m} ; 37$ for 3.1 to $4.5 \mu \mathrm{m} ; 21$ for 4.6 to $6 \mu \mathrm{m}$; 18 for 6.1 to $10 \mu \mathrm{m}$; and 11 for above $10 \mu \mathrm{m}$. Percentage wise, the number comes to $27.5 \%$ for $1-3 \mu \mathrm{m} ; 30.83 \%$ for 3.1 to $4.5 \mu \mathrm{m} ; 17.5 \%$ for 4.6 to $6 \mu \mathrm{m} ; 15 \%$ for 6.1 to 10 $\mu \mathrm{m}$; and $9.17 \%$ for above $10 \mu \mathrm{m}$

For MTA count, the size range was 32 for $1-3 \mu \mathrm{m} ; 26$ for 3.1 to $4.5 \mu \mathrm{m} ; 21$ for 4.6 to $6 \mu \mathrm{m} ; 19$ for 6.1 to $10 \mu \mathrm{m}$; and 22 for above $10 \mu \mathrm{m}$. Percentage wise, the number comes to $26.67 \%$ for $1-3$ $\mu \mathrm{m} ; 21.67 \%$ for 3.1 to $4.5 \mu \mathrm{m}$; $17.5 \%$ for 4.6 to $6 \mu \mathrm{m}$; $15.83 \%$ for 6.1 to $10 \mu \mathrm{m}$; and $18.33 \%$ for above $10 \mu \mathrm{m}$

\section{Discussion}

The material used in the study were water based so mixing these materials with water could induce hydration reaction. Hence, we used alcohol as a replacement of water for preparing the material for the experiment purpose. Other studies such as 18 and 19 also utilized similar type of suspension. The studies also report that dentin tubules density and direction are mostly irregular for human teeth 32. The dentin tubules average diameter is about 2 to $5 \mu \mathrm{m}$. the material used in this study had smaller size in terms of particles and they can easily penetrate in human teeth tubules which can help in creating a hydraulic seal 19. These penetrating particles shows good alkalinity through dentin tubules and may act as the source of ion release which leads to the high local $\mathrm{pH}$ and less chances of reduction due to the buffering in dentin 34 . 
The results of the study show that while comparing the difference between MTA and Portland cement, the MTA showed more percentage of particles in smaller range; while, in chemical enhanced material and Portland cement, the distribution is more in middle and large size particles. This leads to this conclusion that MTA cement has better desirable properties based on particle analysis especially for laboratory uses.

\section{CONCLUSION}

The study purpose was to conduct the comparison of three types of material including Portland cement, calcium enhanced material, and the MTA. The result of particle analysis shows that Portland cement and calcium enhanced material have bigger particles compare to the MTA. the conclusion of the study is that MTA can show better properties based on its small size particles.

\section{References}

Asgary, S., Parirokh, M., Eghbal, M. J., \& Brink, F. (2004). A comparative study of white mineral trioxide aggregate and white Portland cements using X-ray microanalysis. Australian Endodontic Journal, 30(3), 89-92.

Brune, D., \& Smith, D. (1982). Microstructure and strength properties of silicate and glass ionomer cements. Acta Odontologica Scandinavica, 40(6), 389-396.

Camilleri, J., Montesin, F. E., Di Silvio, L., \& Pitt Ford, T. R. (2005). The chemical constitution and biocompatibility of accelerated Portland cement for endodontic use. International endodontic journal, 38(11), 834-842.

Cattani-Lorente, M. A., Godin, C., \& Meyer, J. M. (1994). Mechanical behavior of glass ionomer cements affected by long-term storage in water. Dental Materials, 10(1), 37-44.

Gladys, S., Van Meerbeek, B., Braem, M., Lambrechts, P., \& Vanherle, G. (1997). Comparative physico-mechanical characterization of new hybrid restorative materials with conventional glass-ionomer and resin composite restorative materials. Journal of Dental Research, 76(4), 883-894.

Guggenberger, R., May, R., \& Stefan, K. P. (1998). New trends in glass-ionomer chemistry. Biomaterials, 19(6), 479-483.

Kent, B. E., \& Wilson, A. D. (1971). Dental Silicate Cements: XV. Effect of Particle Size of the Powder. Journal of dental research, 50(6), 1616-1620.

Kogan, P., He, J., Glickman, G. N., \& Watanabe, I. (2006). The effects of various additives on setting properties of MTA. Journal of endodontics, 32(6), 569-572.

Komabayashi, T., \& Spångberg, L. S. (2008). Comparative analysis of the particle size and shape of commercially available mineral trioxide aggregates and Portland cement: a study with a flow particle image analyzer. Journal of endodontics, 34(1), 94-98.

Lee, S. J., Monsef, M., \& Torabinejad, M. (1993). Sealing ability of a mineral trioxide aggregate for repair of lateral root perforations. Journal of endodontics, 19(11), 541-544.

Locher, F. W., Sprung, S., \& Korf, P. (1973). Effects in grinding on cement properties. ZKG Int, 26, 349-355. 
Prentice, L. H., Tyas, M. J., \& Burrow, M. F. (2005). The effect of particle size distribution on an experimental glass-ionomer cement. Dental materials, 21(6), 505-510.

Sulong, M. Z. A. M., \& Aziz, R. A. (1990). Wear of materials used in dentistry: a review of the literature. The Journal of prosthetic dentistry, 63(3), 342-349.

Torabinejad, M., Watson, T. F., \& Ford, T. P. (1993). Sealing ability of a mineral trioxide aggregate when used as a root end filling material. Journal of endodontics, 19(12), 591595

Wang, W., DiBenedetto, A. T., \& Goldberg, A. J. (1998). Abrasive wear testing of dental restorative materials. Wear, 219(2), 213-219.

Wren, A., Clarkin, O. M., Laffir, F. R., Ohtsuki, C., Kim, I. Y., \& Towler, M. R. (2009). The effect of glass synthesis route on mechanical and physical properties of resultant glass ionomer cements. Journal of Materials Science: Materials in Medicine, 20(10), 19911999.

Xie, D., Brantley, W. A., Culbertson, B. M., \& Wang, G. (2000). Mechanical properties and microstructures of glass-ionomer cements. Dental Materials, 16(2), 129-138. 